\title{
Fontes da educação popular na América Latina: contribuições para uma genealogia de um pensar pedagógico decolonial
}

\section{Roots of popular education in Latin America: contributions for a genealogy of decolonial pedagogical thinking}

\author{
João Colares da Mota Neto* \\ Danilo R. Streck**
}

\begin{abstract}
RESUMO
Neste artigo, o objetivo é refletir sobre a emergência de um pensamento pedagógico decolonial na América Latina, tomando por base algumas das principais fontes intelectuais da educação popular nesse continente. Ao entender a educação popular como um "acumulado histórico", que ao longo dos últimos dois séculos vem se afirmando como um movimento de resistência e um discurso pedagógico em favor dos setores populares, traz-se para debate as contribuições intelectuais do brasileiro Paulo Freire (1921-1997) e do colombiano Orlando Fals Borda (1925-2008). Defende-se a ideia de que a educação popular, em sua trajetória histórica, vem contribuindo significativamente para a emergência de uma pedagogia decolonial, capaz de resistir à subalternização dos conhecimentos e das experiências de sujeitos sociais marginalizados pela modernidade/colonialidade.
\end{abstract}

Palavras-chave: Educação Popular. Pedagogia Decolonial. Paulo Freire. Orlando Fals Borda.

* Universidade do Estado do Pará. Programa de Pós-Graduação em Educação. Belém, Pará, Brasil. E-mail: joaocolares@uepa.br. https://orcid.org/0000-0003-3346-1885.

** Universidade do Vale do Rio dos Sinos. Programa de Pós-Graduação em Educação. São Leopoldo, Rio Grande do Sul, Brasil. E-mail: dstreck@unisinos.br. https://orcid.org/0000-00017410-3174. 


\begin{abstract}
In this article, the objective is to reflect on the origins of a decolonial pedagogical thinking in Latin America, based on some of the main intellectual roots of the continent's popular education. Understanding popular education as an "historical accumulation" that in the last two centuries is affirming itself as a movement of resistance and as a pedagogical discourse aligned with the popular sectors of society, the reflection brings to the debate the intellectual contributions of Paulo Freire (1921-1997) and Orlando Fals Borda (1925-2008). It is argued that the idea of popular education, in its historical trajectory, contributes significantly to the emergence of a decolonial pedagogy, capable of resisting to the subjection of knowledge and experiences of social agents marginalized by modernity/coloniality.
\end{abstract}

Keywords: Popular Education. Decolonial Pedagogy. Paulo Freire. Orlando Fals Borda.

\title{
Introdução
}

Em tempos de aprofundamento, tanto na América Latina como em outros continentes, de um modelo educacional elitista e neoliberal, assentado em bases tecnocráticas, em lógicas excludentes e a serviço da reprodução do capitalismo e da colonialidade do poder $^{1}$, trazemos neste artigo, em contrapartida, o debate sobre a educação popular e a pedagogia decolonial como teorias e movimentos de subversão nascidos a partir da luta emancipatória de diferentes sujeitos sociais em Abya Ayala².

Entendemos a decolonialidade, na esteira dos teóricos do programa de investigação da modernidade/colonialidade latino-americano, como um questionamento radical e uma busca de superação de distintas formas de opressão perpetradas pela modernidade/colonialidade contra as classes e os grupos sociais subalternos, sobretudo das regiões colonizadas e neocolonizadas pelas

1 Colonialidade do poder é um dos mais importantes conceitos que o sociólogo peruano Aníbal Quijano e a rede modernidade/colonialidade legaram à teoria crítica da modernidade e do capitalismo. Com ele, Quijano (2005) refere-se a um padrão global de poder, nascido com a colonização da América, e que articula, em uma estrutura heterogênea de poder, as assimetrias de raça, gênero e trabalho, visando o domínio de uns povos sobre outros.

2 Abya Ayla é o nome com que os indígenas Kuna, do Panamá e da Colômbia, chamavam o continente americano antes da Conquista espanhola. Significa "terra de plena maturidade" ou "terra de sangue vital". 
metrópoles euro-norte-americanas, nos planos do existir humano, das relações sociais e econômicas, do pensamento e da educação.

Em outras palavras, decolonialidade pode ser entendida como o esforço por "transgredir, deslocar e incidir na negação ontológica, epistêmica e cosmogônico-espiritual que foi - e é - estratégia, fim e resultado do poder da colonialidade" (WALSH, 2009, p. 27), o que significa, ainda, que ela é uma "energía que no se deja manejar por la lógica de la colonialidad, no si cree en los cuentos de hadas de la retórica de la modernidad" (MIGNOLO, 2007, p. 27).

Por pedagogia decolonial, nesta perspectiva, entendemos o conjunto de teorias-práticas de formação humana que capacitam os grupos subalternos para a luta contra a lógica opressiva da modernidade/colonialidade, tendo como horizonte a formação de um ser humano e de uma sociedade livre, amorosa, justa e solidária. Essa pedagogia deve ser entendida no contexto das lutas decoloniais, que pretendem a viabilização da humanidade contra a matriz colonial e seu padrão de racialização-desumanização que há mais de 500 anos vêm oprimindo e vitimando homens e mulheres (WALSH, 2013).

Com base nessas considerações iniciais e nos seus objetivos, este artigo dimensiona-se como um ensaio teórico que busca recompor, a partir de fontes primárias e em outros estudos biobibliográficos, aspectos da formação do pensamento pedagógico decolonial. A primeira parte será dedicada a uma visão histórica da formação da educação popular. As duas partes seguintes serão dedicadas a Paulo Freire e Orlando Fals Borda, dois pensadores latino-americanos que podem ser considerados predecessores da teoria decolonial no campo da educação e da pesquisa social. Em ambos, os processos educativos e investigativos estão imbricados em princípios ético-políticos e epistemológicos que têm por base a participação dos setores populares na produção do conhecimento acerca de sua realidade enquanto agem pela sua transformação. ${ }^{3}$ Espera-se que o intento de colocá-los em diálogo, como fontes da educação popular no contexto de formação de um pensamento pedagógico decolonial na América Latina que possa servir tanto para explicitar a contribuição da educação popular para os estudos decoloniais quanto para alargar e aprofundar o escopo teórico da própria educação popular com os aportes dos estudos sobre colonialidade.

3 Marcela Gajardo (1986) identifica em Paulo Freire e em Orlando Fals Borda os protagonistas principais de duas vertentes da pesquisa participante na América Latina: Paulo Freire da vertente educacional e Orlando Fals Borda da vertente sociológica. 


\section{A educação popular como um acumulado histórico}

A inspiração para considerarmos a educação popular como um acumulado histórico vem de Mejía (2013), para quem essa tradição pedagógica tem origem nas lutas de independência em nossa pátria grande latino-americana, tornandose movimento e proposta político-pedagógica ao longo dos últimos duzentos anos. "Se reconhecemos que nosso pai é Freire", diz Mejía (2005, p. 212), “o nosso avô é Simón Rodríguez, professor de Simón Bolívar, quem estabeleceu no começo do século XIX as bases da educação popular que a América precisava e que, então, foi proposta para alguns dos pais das repúblicas latino-americanas".

Segundo o entendimento desse autor, a educação popular germina no século XIX a partir de várias fontes, mas destaca, sobretudo, quatro "troncos históricos” originais, que irão confluir, já na segunda metade do século $\mathrm{XX}$, em torno das ideias político-pedagógicas de Paulo Freire. O primeiro tronco vincula-se a pensadores das lutas de independência nos países latino-americanos, entre os quais considera Simón Rodríguez (1769-1854), mestre de Simón Bolívar, como o que mais explicitamente falou de educação popular nesse período. Dentre as ideias deste autor, Mejía (2013) destaca três características do que Rodríguez considerava por educação popular: a) a educação popular nos faz americanos e não europeus, inventores e não repetidores; b) ela educa para que não sejamos mais servos de mercadores e clérigos; c) possibilita uma arte ou ofício para que as pessoas ganhem a vida por seus próprios meios. Nessa mesma linha de pensamento, não pode deixar de ser mencionado José Martí (1854-1895), para quem a educação em Nuestra América deve partir da vida, da realidade e da história das pessoas que aqui vivem, sem deixar de participar dos avanços tecnológicos proporcionados pela ciência moderna, tendo como horizonte um cosmopolitanismo crítico, respeitoso das diferenças (MARTí, 1979).

O segundo tronco liga-se aos intentos de construção de universidades populares ao longo da primeira metade do século XX na América Latina, sendo que as mais notáveis foram as do Peru, El Salvador e México. Nelas se trabalhava para assumir características diferenciadas das outras universidades, particularmente porque: a) educava os operários e alterava, de acordo com os sujeitos desta educação, os conteúdos, os tempos e a maneira de realizar o processo educativo; b) dotava os educandos de consciência sobre o seu lugar e o seu papel na história; c) construía e orientava os educandos rumo a uma organização que defendesse os interesses desses grupos. Uma forte influência nesse movimento se deve ao "Manifiesto de la Federación Universitária de Córdoba" de 21 de junho de 1918 que, ao denunciar a estrutura da universidade e o seu 
isolamento da sociedade, proclamavam estar "pisando sobre una revolución" e "vivendo uma hora americana". ${ }^{4}$

O terceiro tronco vincula-se às experiências dos povos originários, redescobrindo-se hoje a força humana e ecológica através do paradigma do vivir bien da tradição aymara (suma qamaña) ou buen vivir na língua quechua (sumakkawsay). Uma experiência representativa deste tronco foi a escola Ayllu de Warisata (1931-1940) na Bolívia, promovida por Elizardo Pérez (1992). Alguns dos seus fundamentos eram: a) existe uma prática educativa própria dos grupos indígenas, derivada de sua cultura; b) se constituem como "Escolas do esforço", na medida em que desenvolvem uma pedagogia baseada no trabalho; c) a escola se estende e se articula à comunidade, que se torna, ela própria, uma escola.

$\mathrm{O}$ quarto tronco desta história da educação popular envolve projetos educativos diversos ao serviço dos grupos mais desprotegidos da sociedade. Neste sentido, Mejía cita o Padre José María Vélaz e seu intento de construir uma escola a partir da educação popular integral que encontra expressão no Movimento Fé e Alegria, fundado em 1956, e ainda atuante. Esta educação popular integral trabalha com as seguintes ideias: a) a educação visa romper as correntes mais fortes da opressão popular mediante uma educação cada vez mais ampla e qualificada; b) a democracia educativa tem que preceder a democracia econômica e social; c) depois de tanta luta não podemos nos resignar a viver em uma justiça média. Há que lutar pela justiça integral; d) Fé e Alegria nasceu para impulsionar a mudança social por meio da educação popular integral.

Um olhar para a história permite identificar fontes de uma pedagogia decolonial em grande parte invisibilizadas na tradição pedagógica. Referimo-nos especialmente a um conjunto de educadoras que, em lugares diferentes, criaram escolas que contribuíram para a conquista de um lugar no mundo da educação formal para as mulheres. No Brasil, Nísia Floresta (1810-1885) cria escolas para contrapor-se à exclusão das mulheres da produção de conhecimento (FLORESTA, 1989). No Caribe, a cubana Maria Luiza Dolz (1854-1928) levanta sua voz feminina por uma educação igual para meninos e meninas, pleiteando para ambos uma educação para o pleno desenvolvimento dos sentimentos, das ideias e das forças corporais, para alcançarem toda a perfeição de que sejam capazes (DOLZ, 1995).

Por fim, Mejía refere um quinto tronco histórico, constituído a partir da confluência dos demais troncos, que denomina de pedagogia de Paulo Freire, mas que envolve não só as ideias do educador brasileiro, mas também outras construções conceituais críticas surgidas nos anos 1960-1970 na América Latina e que, tanto quanto a educação popular, empreenderam forte crítica ao capitalismo e à colonialidade, como a teoria da dependência, a teologia da

4 Tradução nossa. 
libertação, a comunicação popular, o teatro do oprimido, a filosofia da libertação, a investigação-ação participativa, entre outras.

Ao adotar a periodização de Mejía (2013), precisamos esclarecer, como forma de evitar anacronismos, que reconhecemos a existência de diferenças substanciais entre o que foi chamado de educação popular no século XIX e o que passou a ser educação popular no século XX. ${ }^{5}$ As condições de produção do discurso, as bases epistemológicas e os contextos históricos particulares de cada momento não nos permitem fazer generalizações apressadas, de modo que, se falamos em "acumulado histórico", não entendemos que se trata de uma continuidade retilínea e sem rupturas.

Porém, apesar dessas diferenças, as quais não nos cabe aprofundar neste artigo, consideramos que a educação popular da segunda metade do século XX possui antecedentes e fontes de inspiração que fazem parte da história de resistência e da inventividade pedagógica na América Latina. Isso nos permite caracterizar, historicamente, a educação popular como uma das tradições pedagógicas mais originais nascidas na América Latina. Não se trata apenas de um pensamento educacional, mas também de um movimento de educadores, profundamente conectados com a história do continente, com realidade própria das classes populares latino-americanas, suas experiências reais, seus saberes ancestrais, suas necessidades e seus projetos de vida.

\section{Paulo Freire e a pedagogia do oprimido}

Paulo Freire é um autor cuja obra tem sido estudada em todo o mundo, com uma variedade muito grande de perspectivas de análise e orientações epistemo-metodológicas ${ }^{6}$. Reconhecido como um dos mais importantes educadores do século XX, seu pensamento é um "patrimônio incontornável da reflexão pedagógica atual", funcionando como "uma espécie de consciência crítica,

5 Oscar Jara Holliday (2017), em sua tese de doutorado, analisa o desenvolvimento atual da educação popular e identifica cinco períodos entre os anos 1959 e 2017 que teriam, respectivamente, os seguintes marcos: o governo da Unidade Popular no Chile, a Revolução Cubana, a Revolução Sandinista na Nicarágua, o levante Zapatista no México e o primeiro Fórum Social Mundial no Brasil.

6 Para uma visão abrangente e diversa sobre a vida e a obra de Paulo Freire, remetemos o leitor ao livro "Paulo Freire: uma biobibliografia", organizado por Gadotti (1996) e ao "Dicionário Paulo Freire", organizado por Streck; Redin e Zitkoski (2016), com um conjunto de verbetes sobre categorias e conceitos provenientes da obra de Paulo Freire. Como exemplos dos novos impulsos para a compreensão da obra de Paulo Freire podem ser citados os livros "O educador: um perfil de Paulo Freire", de Sérgio Haddad (2019), e "Paulo Freire mais do que nunca: uma biografia filosófica" de Walter Kohan (2019). 
que nos põe em guarda contra a despolitização do pensamento educativo e da reflexão pedagógica" (NÓVOA, 1998, p. 187).

Há um caráter heterodoxo e não-dogmático de sua obra, que possibilita que seu legado seja reinventado e (re)apropriado criticamente por educadores e lutadores sociais de distintas latitudes. Nesta direção, concordamos com Torres (2007) quando afirma que a leitura desse educador, ao redor do mundo, tem sido múltipla, revelando-se uma "infinitude" de Freires. Aliás, o próprio Freire insistia na necessidade de que seus estudiosos não o dogmatizassem, e sim o reinventassem, sem perder de vista, em todo caso, a substantividade de suas ideias, isso é, sem distorcê-lo, sem descaracterizá-lo, sem ignorar os núcleos centrais de seu pensamento. Desse modo, defendemos nesse ensaio que uma de suas ideias mais substanciais é a de uma educação descolonizadora, capaz de libertar as mentalidades da lógica opressiva da colonialidade e de mobilizar as classes subalternas para o enfrentamento das estruturas assimétricas de poder instituídas pela modernidade/colonialidade (MOTA NETO, 2016).

Um aspecto fundamental do pensamento decolonial está relacionado ao lócus enuntiationis ocupado pelo sujeito que produz a teoria, que elabora o discurso, que reivindica posições críticas da colonialidade e do colonialismo. Este lugar está marcado pela exterioridade de sujeitos, grupos e populações periféricos, no sentido de que foram subalternizados pela modernidade/colonialidade. Estando, portanto, em uma posição exterior, tais sujeitos/grupos/ populações podem revelar a colonialidade escondida pela retórica salvacionista da modernidade e mobilizar a articulação de forças/ideias decoloniais.

Ao realizar a leitura de suas obras, encontramos claramente sua identificação com este lugar de enunciação marcado pela exterioridade. Em Cartas à Guiné-Bissau, por exemplo, Freire assume-se como um "homem do Terceiro Mundo, como educador com este mundo comprometido" (1978, p. 91); em Pedagogia da Autonomia, Freire (1996) diz que o seu ponto de vista é o dos condenados da terra, dos excluídos; em diálogo com Sérgio Guimarães, no livro A África ensinando a gente, Freire afirmava sentir-se profundamente latino-americano, brasileiro, recifense (FREIRE; GUIMARÃES, 2011, p. 43-44).

Deste modo, entendemos que a biografia de Paulo Freire o conduziu a pensar a pedagogia a partir dos subalternos; que o oprimido não é o sujeito para quem fala Paulo Freire, mas com quem fala; que ele mesmo, nas lutas político-educacionais que vivenciou no Brasil, em outros países da América Latina, nos Estados Unidos, na Europa e na África, ocupou discursiva e geopoliticamente o lugar do oprimido; e que, portanto, isso marca fundamentalmente sua obra como um testemunho crítico da modernidade/colonialidade, logo, como um pensador decolonial.

Para além deste traço biográfico, Freire, desde os seus primeiros trabalhos, apresenta preocupações, constrói conceitos e discute questões as quais hoje podemos 
chamar de "decoloniais". Ainda tomando por base o estudo de Mota Neto (2016), consideramos que o eixo fundamental de sua concepção decolonial está relacionado à crítica de seis fenômenos moderno-coloniais: a) crítica à inexperiência democrática da sociedade brasileira, herdeira de um regime colonial ou semicolonial; b) crítica à desumanização/massificação/coisificação do ser humano; c) crítica à teoria antidialógica da opressão e, em especial, à invasão cultural; d) crítica ao problema da dependência nas relações imperialistas e neocoloniais entre o Primeiro e o Terceiro Mundo; e) crítica à educação e aos sistemas de ensino coloniais; f) crítica à razão determinista da modernidade e à pós-modernidade neoliberal.

No conjunto, em seus quarenta anos de produção intelectual, Freire denunciou distintos aspectos do colonialismo e da colonialidade: a educação bancária, a cultura do silêncio, a invasão cultural, a violência, a desumanização, o patriarcado, o racismo, o latifúndio, o autoritarismo político, o assistencialismo, a situação de dependência dos países periféricos em relação aos centrais e o cientificismo.

Essas são críticas que alcançam, de modo integrado, questões pedagógicas, sociológicas, antropológicas, políticas, éticas e epistemológicas. Desse modo, a denúncia de Freire à vigência do colonialismo é não só radical, como também bastante abrangente, dimensionando um pensamento dialético e complexo, capaz de analisar a força do colonialismo nas relações entre subjetividade e objetividade, cultura e economia, política e ética, ciência e senso comum.

Podemos encontrar um exemplo de sua crítica em um pequeno texto intitulado "Descobrimento da América", redigido em 1992, como resposta à "encuesta" realizada pela Fundação de Investigações Sociais e Políticas do Centro Ecumênico de Educação Popular, de Buenos Aires, no contexto do V Centenário do chamado "Descobrimento da América". Sobre a questão do "descobrimento" da América, temática que estava em consulta, Freire (2000) diz que não poderia falar nada a respeito, porque o que houve não foi descobrimento, mas "conquista", e sobre tal, o seu pensamento, em definitivo, era o de recusa.

Nesse excerto, Freire reconhece a diferença entre colonialismo (conquista do espaço físico, poder avassalador sobre as terras e as gentes) e colonialidade (presença predatória no espaço histórico e cultural do invadido, incontida ambição de destruir a identidade cultural dos nacionais) e é também crítico do mito da modernidade (a tentativa de "amaciar" a invasão ao vê-la como um presente "civilizatório"), questões que são basilares ao pensamento decolonial latino-americano.

7 Este conceito está presente na obra de Enrique Dussel (2008), para quem a modernidade, apresentada em sua "retórica salvacionista", constitui uma estratégia discursiva que oculta a violência colonizadora praticada em nome da razão, do progresso, do desenvolvimento, promessas explicitadas, inclusive, pelas mais avançadas filosofias europeias, de que é exemplar a Filosofia do Espírito de Hegel. 
Freire (2000, p. 74), nesse texto, também denuncia a “malvadez" intrínseca a qualquer forma de colonialismo, oferecendo contributos para alongar o conceito de colonialidade do $\operatorname{ser}^{8}$. E, em mais uma reflexão claramente decolonial, valoriza a história de luta contra o colonialismo e a colonialidade mobilizada por parte das classes populares, indígenas, negros. Desse modo, diz ele que ao invés de comemorar o falso "descobrimento", deveríamos valorizar "a coragem, a rebeldia, a decisão de brigar, a bravura, a capacidade de lutar contra o invasor; a paixão pela liberdade, de índios e índias, de negros e negras, de brancos e brancas, de mamelucos, que tiveram seus corpos rasgados, seus sonhos despedaçados, suas vidas roubadas".

Essa resistência, já manifestada desde o período colonial, continua presente nos dias de hoje, através de outras estratégias e movimentos de luta. Segundo o autor: 'Seus gestos de rebeldia se repetem hoje na luta dos 'sem-terra', dos 'sem-escola', dos 'sem-casa', dos favelados; na luta contra a discriminação racial, contra a discriminação de classe, de sexo" (FREIRE, 2000, p. 74-75).

Mas não só crítico do colonialismo, Freire também se engajou na construção de propostas político-pedagógicas descolonizadoras, tanto no Brasil quanto em outros países da América Latina e da África, sem deixar de mencionar sua atuação nos Estados Unidos e na Europa, considerando também existir um Terceiro Mundo no interior do Primeiro (FREIRE, 1982).

A pedagogia do oprimido que defendeu e praticou marca uma ruptura em relação às pedagogias colonizadoras, por um conjunto de motivos: a) supera o colonialismo epistemológico segundo o qual a razão está sempre no educador, representante da ciência hegemônica, e nunca no educando; b) define as classes populares como sujeitos da história, da educação e da investigação, superando a dicotomia sujeito e objeto; c) valoriza a sabedoria popular e a história local, oferecendo possibilidades de construir conhecimento a partir de cosmovisões ancestrais, anteriores ao processo colonizador; d) empodera as classes e os grupos populares, devido ao seu viés conscientizador e mobilizador; e) engendra um diálogo intercultural que viabiliza a restauração da humanidade dos sujeitos e do mundo; f) enfatiza a participação cidadã e democrática, criando uma fissura na cultura do silêncio e na colonialidade do poder.

8 Este conceito pode ser lido como um desdobramento das noções de colonialidade do poder e colonialidade do saber, e ele está referido, segundo Maldonado-Torres (2007), à experiência vivida da colonização e seu impacto na linguagem. Somando-se, assim, a abordagens que perscrutam as implicações da colonialidade nas relações raciais e de trabalho, bem como nos saberes e nas epistemologias dominantes, a colonialidade do ser abrange as consequências de todas essas formas de domínio no existir humano, na sua corporalidade, na vida negada dos povos colonizados, sobretudo os negros e indígenas. 
Por essas e outras razões, defendemos que o pensamento de Paulo Freire constitui uma fonte fundamental para a constituição de uma pedagogia decolonial na América Latina, na medida em que mobiliza os grupos subalternos a lutarem autonomamente pela transformação da sociedade e superação dos mais diversos legados do colonialismo.

\section{Orlando Fals Borda e a sociologia sentipensante}

Sociólogo prolífico, autor de dezenas de obras sobre uma variedade de temáticas, como sociologia rural, epistemologia das ciências sociais e educação popular, Orlando Fals Borda se destacou como um dos mais importantes cientistas sociais latino-americanos, tendo contribuído para a formulação da chamada sociologia da libertação dos anos 1960-1970, além da investigação-ação participativa (IAP), método pelo qual viria a ser conhecido por pesquisadores participativos em todo o mundo. ${ }^{9}$

Para Borja (2012), Fals Borda foi o pioneiro de uma ciência humana autônoma e gestada a partir das próprias entranhas da América Latina; um líder que atuou e pensou uma sociedade justa e outro tipo de Estado capaz de tornar viável essa sociedade imaginada; um criador de instituições e práticas políticas orientadas a mudar a situação de prostração intelectual e material mediante uma vida de compromisso social; um pensador que contribuiu significativamente para libertar as ciências sociais latino-americanas do colonialismo intelectual.

Sánchez (2008), por sua vez, considera Fals Borda como um "herói cultural", um autor que faz parte de uma plêiade de pensadores latino-americanos que irromperam com ímpeto e seriedade nas reformulações sobre os problemas e os rumos a seguir em nossos países, como Celso Furtado, Aníbal Quijano, Florestan Fernandes e Pablo González Casanova.

Estamos de acordo com essas caracterizações e afirmamos que a concepção decolonial em Orlando Fals Borda se articula por meio da conjunção de sua trajetória como intelectual crítico sentipensante e de sua contumaz reação ao colonialismo político e epistemológico, que o levam não somente a defender uma sociologia da libertação e uma ciência social desapegada do euro-norte-centrismo dominante, como também a propor e protagonizar um projeto ético-político de

9 Um conjunto de obras de Fals Borda pode ser encontrado na antologia "Uma sociologia sentipensante para América Latina”, organizada por Victor Manuel Moncayo. Também disponível na biblioteca virtual da CLACSO: http://biblioteca.clacso.edu.ar/clacso/se/20151027053622/AntologiaFalsBorda.pdf. Acesso em: 03 out. 2019. 
sociedade participativa, baseada nos valores socioculturais fundantes das populações originárias da América Latina. A educação popular, nesta perspectiva, relacionada a processos investigativo-participativos, deveria contribuir para a superação do colonialismo epistemológico e para a construção de uma sociedade emancipada e livre (MOTA NETO, 2016).

Fals Borda (2003, p. 9) definiu como sentipensante "aquella persona que trata de combinar la mente con el corazón, para guiar la vida por el buen sendero y aguantar sus muchos tropiezos". Trata-se, assim, de uma aposta na possibilidade de um outro perfil de educador, de investigador, de militante e de intelectual, em franca oposição à atitude fria e supostamente neutra do cientista positivista, tradicional e eurocêntrico.

O estudo sobre a vida de Fals Borda nos mostra que ele não somente defendeu tais ideias, como foi testemunho vivo de sua possibilidade. Ao longo de sua trajetória, sobretudo nas vivências de investigação participativa, Fals Borda construiu vínculos democráticos e afetivos com as comunidades investigadas (consideradas também investigadoras), o que significou uma recusa da relação vertical e autoritária que tradicionalmente tem marcado o trabalho de cientistas sociais e educadores. Com efeito, criou vínculos orgânicos com diversos movimentos sociais, sobretudo campesinos, participando ativamente de processos de luta e transformação social na Colômbia, sua terra natal, mas também em outros países do mundo.

Um aspecto importante de sua concepção decolonial radica nas contundentes críticas que elaborou ao chamado colonialismo intelectual, em diversos escritos desde os anos 1970. No clássico Ciencia propia y colonialismo intelectual, Fals Borda (1970) defende que respondamos aos desafios do trópico e do subtrópico com nossos próprios meios, concebendo nossas próprias soluções com base em ideologias criadas aqui, utilizando e valorizando nossa cultura. Essa solução, para ele, é preferível a seguir sendo uma cópia de segunda classe e um simples mercado de um povo estranho.

Defendia, nestes termos, que a independência cultural, técnica e científica da América Latina é uma condição, embora não a única, para a independência política e econômica da região. Para isso, em primeiro lugar, seria necessário descartar nosso complexo de inferioridade, sem necessariamente ser chauvinista e sem negar o desenvolvimento geral das ciências em outros contextos. Em segundo lugar, seria preciso criar grupos de referência dentro do nosso próprio meio, de modo que pudéssemos falar mais entre nós e para nós. O terceiro aspecto seria trabalhar arduamente com nossos materiais e sobre nossas realidades, tratando de articular nossas respostas com fórmulas, conceitos e marcos de referência produzidos aqui mesmo (FALS BORDA, 1970). 
O desafio proposto por Fals Borda era o de construir uma ciência própria, que também chamou de rebelde, subversiva, comprometida, e que fosse não apenas insurgente, como também humilde, direcionada para as camadas populares, uma ciência modesta (o que não significa que fosse de segunda classe ou sem critérios), mas uma ciência sem desenhos "estrambóticos", nem complicações desnecessárias, mas útil aos fins que persegue. Para chegar a esse caminho, teríamos que seguir a via estreita e difícil da autodeterminação cultural e política e assumir nossa dignidade.

À luz desta concepção de ciência, contribuiu para formular a chamada investigación-acción participativa (IAP). A IAP foi concebida, a um só tempo, como um método de investigação, uma técnica educativa e uma ação política. Não se trata de somente investigar, nem somente educar, nem somente atuar. É uma tríade permeada por uma filosofia de vida, que a satura como um todo e com a qual se poderia reconstruir a sociedade como uma força nova. A IAP é, desse modo, uma metodologia dentro de um processo vivencial (FALS BORDA; ZAMOSC, 1985).

Ao combinar a pesquisa científica com a ação política, a IAP visa transformar radicalmente a realidade social e econômica e construir o poder popular em benefício dos excluídos. Neste complexo processo estão incluídos a educação popular, o diagnóstico das situações, a análise crítica e a prática como fontes do conhecimento para sondar os problemas, as necessidades e as dimensões da realidade (FALS BORDA, 1985).

Os propósitos finais da IAP, neste sentido, são os de: a) capacitar as classes e grupos explorados para engendrar com eficácia o peso transformador que lhes corresponde, traduzido em projetos, obras, lutas e desenvolvimentos concretos; e b) produzir e elaborar o pensamento sociopolítico próprio de tais bases populares (FALS BORDA, 1985).

Consideramos a IAP como uma experiência político-pedagógica, no preciso sentido da educação popular, na medida em que busca armar ideológica e intelectualmente as classes mais exploradas da sociedade, para que estas assumam conscientemente o seu papel como atores da história. Para Fals Borda (1978), este é o destino final do conhecimento, validado pela práxis e orientado pelo compromisso revolucionário.

Seguindo o sentido da educação popular como processo político-pedagógico de organização das camadas populares, Fals Borda (1985) considerava a IAP como um método científico de trabalho produtivo (e não apenas de investigação), que implica organizar e impulsionar movimentos sociais de base, de modo que resulta difícil e improdutivo distinguir entre estudo e militância.

Esta convergência entre a IAP e a educação popular tem se aprofundado desde os anos 1970, e disso resultaram práticas educativas e de investigação 
eminentemente decoloniais, em nosso entendimento, porque contribuíram para: a) romper a dualidade sujeito/objeto que caracteriza o conhecimento no paradigma científico moderno; b) subverter a dicotomia entre conhecimento científico e sabedoria popular, que tem sido uma arma ideológica do pensamento eurocêntrico para determinar a inferioridade das cosmovisões das classes populares; c) ultrapassar a neutralidade valorativa e o descompromisso com a transformação social típicas das ciências positivistas. ${ }^{10}$

No esteio dessa convergência, Fals Borda (2010 [1995]) propunha uma educação popular pesquisadora e participativa, um processo pedagógico pelo qual se pudesse recuperar a história esquecida das lutas populares, valorizar nossas próprias raízes como povo, comunicar os resultados do trabalho, levando em conta os níveis de compreensão das comunidades e construir um efetivo e rico diálogo entre saberes.

\section{Considerações finais}

Neste artigo debatemos sobre a educação popular como uma concepção e movimento que deve estar inserida na genealogia de um pensar pedagógico decolonial na América Latina. Paulo Freire e Orlando Fals Borda, as referências centrais em nossa reflexão, são intelectuais e educadores chaves para compreender um movimento pedagógico que acompanha as lutas de cunho decolonial e emancipatório em Abya Ayala, interconectadas com as lutas de povos em outros lugares, como atestam as suas andarilhagens pelo mundo.

O continente latino-americano é um território marcado por profunda exploração e desigualdade. Porém, por sua própria condição de periferia do sistema-mundo, irrompeu ao longo da história, como contrapartida à dominação, um manancial de lutas e resistências, de que são protagonistas os coletivos populares que procuraram reescrever a história com seus próprios valores, cosmovisões e ideais.

Estes coletivos, ao questionarem as pedagogias hegemônicas, colonizadoras, racistas e patriarcais, assumiram-se como construtores de pedagogias decoloniais, interessadas em visibilizar e superar as matrizes assimétricas de poder da modernidade/colonialidade. Construíram pedagogias populares, inter-

10 Dentre essas práticas merece destaque a sistematização de experiências que se situa na interface entre pesquisa, formação e avaliação/ação (JARA HOLLIDAY, 2012; BARRAGÁN CORDERO; TORRES CARRILLO, 2017). 
culturais, emancipadoras, assentadas em valores éticos e que apontam para um outro horizonte societário, no qual devem prevalecer a justiça e a solidariedade.

Não há uma única pedagogia decolonial em nosso continente. Ao longo da história, ela tem assumido formatos distintos e se articulado com territórios, sujeitos e movimentos os mais diversos, assim como, no plano epistemológico, não são homogêneas as bases que sustentam as formulações decoloniais. No entanto, defendemos nesse artigo que a educação popular é uma das mais importantes fontes de um pensar pedagógico decolonial, seja pelas experiências concretas de luta contra as opressões, seja pela formulação de um pensamento educacional original, crítico e libertador.

Ao mesmo tempo, reconhece-se que a educação popular é um conjunto de práticas educativas e de movimentos pedagógicos que acompanham a dinâmica da sociedade em busca de superação de heranças coloniais sedimentadas em estruturas sociais e internalizadas na consciência que se expressam na forma de exploração econômica, de patriarcalismo, de racismo e, não por último, na forma como nos relacionamos com o conhecimento (TORRES CARRILLO, 2016). Nesse sentido, o atual diálogo com os estudos decoloniais permite a interlocução com atores, contextos e práticas que trazem para o campo da educação popular outras vozes e outros rostos.

Uma das características do pensamento decolonial é precisamente a ruptura com a rigidez disciplinar da ciência moderna. Em Paulo Freire e Fals Borda temos tanto o permanente diálogo entre conhecimento acadêmico e saberes do cotidiano, quanto o diálogo entre disciplinas distintas. Fals Borda refere-se às "convergências disciplinares" na pesquisa ação quando sociólogos, antropólogos, teólogos, artistas e outros profissionais se encontravam para nomear e transformar o mundo junto com os campesinos (FALS BORDA, 2010, p. 360). $\mathrm{O}$ mesmo acontece com a investigação dos temas geradores na prática alfabetizadora de Paulo Freire, conforme relatado na Pedagogia do oprimido (FREIRE, 1981). Ou seja, a educação popular na acepção de Freire e Fals Borda representa também um esforço de descolonizar a forma como se produz o conhecimento.

Paulo Freire e Orlando Fals Borda representam, por um lado, a consolidação de um pensamento educacional que foi se formando ao longo da história a partir das raízes escondidas no solo, mas que alimentam uma grande riqueza de práticas educativas e de reflexões sobre o que é a educação e para o que ela serve. Por outro lado, ambos são parte desta história e devem ser vistas como elos ou como fontes inspiradoras para novas experiências e para novas teorizações. Mais do que em outros tempos, este movimento se dá em interconexões globais, no diálogo com educadores e educadoras em outras partes do mundo que lutam contra as mesmas forças desumanizadoras e destruidoras da vida, e 
que lutam - como argumentamos neste artigo - pela superação das relações de colonialidade do saber, do ser e do poder.

\section{REFERÊNCIAS}

BARRAGÁN CORDERO, Disney; TORRES CARRILLO, Alfonso. La sistematización como investigación interpretativa crítica. Bogotá, DC: El Búho, 2017.

BORJA, Miguel. Orlando Fals Borda y la sociedad colombiana. In: BORJA, Miguel; PINEDA, Jacinto; VIZCAÍNO, Milcíades. Orlando Fals Borda: una vida de compromiso social. Bogotá: Escuela Superior de Administración Pública, 2012.

DOLZ, Maria Luiza. Educación y dirección de laniñez. Revista Educación, Cuba, 1995, n. 86, p. $38-46,1995$.

DUSSEL, Enrique. 1492, El encubrimiento del Otro: Hacia el origen del "Mito de la modernidad”. La Paz: Biblioteca Indígena, 2008.

FALS BORDA, Orlando. Ciencia Propia y Colonialismo Intelectual. Ciudad de México: Editorial Nuestro Tiempo, 1970.

. Por la praxis: el problema de cómo investigar la realidad para transformarla. In: et al. Crítica y Política en Ciencias Sociales: el debate sobre teoría y práctica. Bogotá: Punta de Lanza, 1978.

. Conocimiento y poder popular: Lecciones con campesinos de Nicaragua, México, Colombia. Bogotá: Punta de Lanza; Siglo Veintiuno Editores, 1985.

. Ante la crisis del pais: ideas-acción para el cambio. Bogotá: El Áncora Editores; Panamericana Editorial, 2003.

. Una sociología sentipensante para América Latina. Compilado por Victor Manuel Moncayo. Bogotá: Siglo del Hombre y Clacso, 2009.

. La investigación-Acción en convergencias disciplinarias. In: Antología Orlando Fals Borda. Bogotá: Universidad Nacional de Colombia, 2010, p. 359-368.

. Pesquisa-Ação, ciência e educação popular nos anos 90. In: STRECK, Danilo (Org.). Fontes da Pedagogia Latino-Americana: uma antologia. Belo Horizonte: Autêntica Editora, 2010 [1995].

; ZAMOSC, León. Balance y perspectivas de la IAP. In: GARCÍA, Carlos (Org.). Investigación Acción Participativa en Colombia. Bogotá: Punta de Lanza; Foro Nacional por Colombia, 1985. 
FREIRE, Paulo. Cartas à Guiné Bissau: registros de uma experiência em processo. 4. ed. Rio de Janeiro: Paz e Terra, 1978.

. Pedagogia do oprimido. 9. ed. Rio de Janeiro: Paz e Terra, 1981. Terra, 1982.

. Ação cultural para a liberdade e outros escritos. 6. ed. Rio de Janeiro: Paz e

. Pedagogia da Autonomia: saberes necessários à prática educativa. São Paulo: Paz e Terra, 1996.

. Pedagogia da indignação: cartas pedagógicas e outros escritos. São Paulo: Editora UNESP, 2000.

; GUIMARÃES, Sérgio. A África ensinando a gente: Angola, Guiné-Bissau, São Tomé e Príncipe. 2. ed. São Paulo: Paz e Terra, 2011.

FLORESTA, Nísia. Direitos das mulheres e injustiça dos homens. São Paulo: Cortez, 1989.

GADOTTI, Moacir (Org.). Paulo Freire: uma biobibliografia. São Paulo: Cortez Editora; Instituto Paulo Freire, 1996.

GAJARDO, Marcela. Pesquisa participante na América Latina. São Paulo: Brasiliense, 1986.

HADDAD, Sérgio. O educador: um perfil de Paulo Freire. São Paulo: Todavia, 2019.

JARA HOLLIDAY, Oscar. A sistematização de experiências: prática e teoria para outros mundos possíveis. Brasília, DF: Contag, 2012.

. Educación y cambio social em América Latina: Interpretación crítica de las contribuciones ético-políticas y pedagógicas de la Educación Popular Latinoamericana 1959-2017. Tese apresentada ao Doctorado Latinoamericano de Educación, Universidad de Costa Rica, 2017.

KOHANN, Walter. Paulo Freire mais do que nunca: uma biografia filosófica. Belo Horizonte: Vestígio, 2019.

MALDONADO-TORRES, Nelson. Sobre la colonialidad del ser: contribuciones al desarrollo de un concepto. In: CASTRO-GÓMEZ, Santiago; GROSFOGUEL, Ramón (Orgs.). El Giro Decolonial: reflexiones para una diversidad epistémica más allá del capitalismo global. Bogotá: Siglo del Hombre Editores; Universidad Central, Instituto de Estudios Sociales Contemporáneos, Pontificia Universidad Javeriana, Instituto Pensar, 2007.

MANIFIESTO de la Federación Universitaria de Córdoba. Revista Ensino Superior Unicamp p. 74. Disponível em: http://www.gr.unicamp.br/ceav/revistaensinosuperior/ ed03 junho2011/pdf/11.pdf. Acesso em: 16 jul. 2018.

MARTÍ, José. On Education. Articles on Educational Theory and Pedagogy, and Writings for Children from "The Age of Gold”. Edited by Philip S. Foner. New York: Monthly Review Press, 1979. 
MEJÍA, Marco Raúl. Aprofundar na Educação Popular para construir uma globalização desde o Sul. In: UNESCO. Educação Popular na América Latina: diálogos e perspectivas. Brasília: UNESCO, MEC, CEAAL, 2005.

. Posfácio - La Educación Popular: una construcción colectiva desde el sur y desde abajo. In: STRECK, Danilo; ESTEBAN, Maria Teresa (Orgs.). Educação Popular: lugar de construção social coletiva. Petrópolis: Vozes, 2013.

MIGNOLO, Walter. El Pensamiento Decolonial: Desprendimiento y Apertura. Un manifesto. In: CASTRO-GÓMEZ, Santiago; GROSFOGUEL, Ramón (Orgs.). El Giro Decolonial: Reflexiones para una diversidad epistémica más allá del capitalismo global. Bogotá: Siglo del Hombre Editores; Universidad Central, Instituto de Estudios Sociales Contemporáneos, Pontificia Universidad Javeriana, Instituto Pensar, 2007.

MOTA NETO, João Colares da. Por uma pedagogía decolonial na América Latina: reflexões em torno do pensamento de Paulo Freire e Orlando Fals Borda. Curitiba: CRV, 2016.

NÓVOA, António. Paulo Freire (1921-1997): a "inteireza” de um pedagogo utópico. In: APPLE, Michael; NÓVOA, António (Orgs.). Paulo Freire: política e pedagogia. Portugal: Porto Editora, 1998.

PÉREZ, Elizardo. Warisata: la escuela ayllu. La Paz: HISBOL/CERES, 1992.

QUIJANO, Aníbal. Colonialidade do poder, eurocentrismo e América Latina. In: LANDER, Edgardo (Org.). A colonialidade do saber: Eurocentrismo e ciências sociais. Perspectivas latino-americanas. Buenos Aires: CLACSO, 2005.

SÁNCHEZ, Ricardo. Orlando Fals Borda: héroe cultural. Ciencia Politica, n. 6, p. 9-17, julio-diciembre 2008.

STRECK, Danilo; REDIN, Euclides; ZITKOSKI, Jaime José (Orgs.). Dicionário Paulo Freire. Belo Horizonte: Autêntica, 2016.

TORRES, Rosa María. Los múltiples Paulo Freires. Educación de Adultos y Desarrollo - DVV International, n. 69, p. 15-29, 2007.

TORRES CARRILLO, Alfonso. Educación popular y movimientos sociales en América Latina. Buenos Aires: Biblos, 2016.

WALSH, Catherine. Interculturalidade, crítica e pedagogia decolonial: in-surgir, re-existir e re-viver. In: CANDAU, Vera Maria (Org.). Educação intercultural na América Latina: entre concepções, tensões e propostas. Rio de Janeiro: 7 Letras, 2009.

. Lo pedagógico y lo decolonial: Entretejiendo caminos. In: WALSH, Catherine (Ed.). Pedagogías decoloniales: Prácticas insurgentes de resistir, (re)existir y (re)vivir. Quito: Ediciones Abya-Yala, 2013.

Texto recebido em 09/03/2019.

Texto aprovado em 02/10/2019. 